\title{
The influence of sex and puberty on the progression of diabetic nephropathy and retinopathy
}

\author{
J. N. Harvey
}

Received: 11 April 2011 /Accepted: 20 April 2011 /Published online: 21 May 2011

(C) Springer-Verlag 2011

Keywords Diabetic nephropathy Diabetic retinopathy. Sex $\cdot$ Type 1 diabetes

$\begin{array}{ll}\text { Abbreviations } \\ \text { EDIC } & \begin{array}{l}\text { Epidemiology of Diabetes Interventions and } \\ \text { Complications }\end{array} \\ \text { ESRD } & \text { End-stage renal disease } \\ \text { MMP } & \text { Mesangial metalloproteinase } \\ \text { PKC } & \text { Protein kinase C } \\ \text { SERM } & \text { Selective oestrogen receptor modulators }\end{array}$

With the current insulins, treatment regimens, monitoring systems and devices, severe hyper- and hypoglycaemia can largely be avoided. Increasingly, it is prevention of the long term complications of diabetes that has become the focus of modern diabetes care, especially in childhood onset diabetes, where the lifetime potential for morbidity and excess mortality is greatest. Achieving a better understanding of predisposing factors and mechanisms involved is therefore important.

In this issue of Diabetologia, Harjutsalo et al. report the cumulative incidence of end-stage renal disease (ESRD) and laser treated retinopathy in a large cohort of patients with early onset type 1 diabetes in Finland [1]. They show the male preponderance of both nephropathy and retinopathy, which has been identified previously. But here, the adverse influence of male sex is very clearly related to age

\section{J. N. Harvey $(\bowtie)$}

Centre for Endocrine and Diabetes Sciences, Wales College of Medicine, Cardiff University, Gladstone Centre, Maelor Hospital, Wrexham LL13 7TD, UK

e-mail: john.harvey@wales.nhs.uk at onset of diabetes, being apparent only with pubertal onset, and remaining high with onset after age 15 years. The excess risk in men increases with duration of diabetes.

A nationwide study from Sweden of the relationship of age at onset of type 1 diabetes and sex with eventual ESRD has also recently reported [2]. These authors similarly find a lower incidence of ESRD in patients with prepubertal onset of diabetes. Here, the group with age at onset of diabetes in the range 20-34 years had the greatest subsequent male preponderance of ESRD. The incidence of ESRD was lower in Sweden than Finland, such that the risk in females with postpubertal onset of diabetes was no different from the prepubertal onset diabetes group.

These data offer us a number of insights. First, that sex steroids or other pubertal hormones related to sex influence the risk of both subsequent nephropathy and retinopathy. The influence of sex on retinopathy outcome has been more controversial, although some previous studies have shown a similar increased risk in men [3], now confirmed by the larger analysis from Finland [1]. Both of the new analyses show an increasing difference in renal outcome over time between men and women, but only in the groups with onset of diabetes at puberty or later. The Swedish study is larger but has a shorter follow-up and lower incidence of ESRD. Otherwise, the results are similar. The retinopathy data from Finland shows a broadly similar pattern of progression. With prepubertal onset of diabetes, the progressively increasing difference in outcome between the sexes does not occur. This would seem to be strong evidence for microvascular injury related to sex occurring at the time of diagnosis, if that is at puberty or later. The levels of male hormones and other factors that influence the development of nephropathy (glycaemia, blood pressure, smoking, etc.) over many years of adult life seem likely to be little 
different between those who developed diabetes before puberty and those after puberty. Thus, there is a clear implication that onset at puberty or later results in some form of renal and retinal injury that allows the development of microvascular disease many years afterwards. Men are much more susceptible to this than women. Increased testosterone or reduced sex hormone binding globulin has been associated with the development of microalbuminuria in a younger group [4], but not when studied in an older population of type 1 diabetic patients [5], and has also been found to be associated with proliferative retinopathy $[6,7]$. However, these findings do not seem to explain the difference in microvascular outcome between prepubertal and postpubertal onset of diabetes.

The results of these analyses reinforce the concept that what happens early in the course of diabetes has implications for events many years later. The Epidemiology of Diabetes Interventions and Complications (EDIC) study showed that a period of intensive glycaemic control (during the DCCT study) resulted in a clear reduction in the incidence of nephropathy 7-8 years after the DCCT study had concluded, despite no difference in glycaemic control during that subsequent (post DCCT) period [8]. The present study appears to show a similar 'legacy effect' in that the impact of male sex and diabetes onset at puberty is manifest many years later.

That puberty has an influence on the development of nephropathy has been known for many years. Krowleski et al. first showed that patients with prepubertal onset of diabetes took longer to develop nephropathy [9]. Changes in renal function in the diabetic kidney occur at puberty with more rapid increase in albuminuria during puberty, compared with before puberty, even within the normal range $[10,11]$. Persistent microalbuminuria (measured as excretion rate) occurs only from puberty [12] but structural evidence of nephropathy-increased basement membrane thickness and mesangial expansion - is present earlier [13]. Glomerular hyperfiltration occurs early in the course of diabetes and may predict the development of nephropathy [14]. Based on micropuncture studies in Munich-Wistar rats it has been suggested that this haemodynamic phenomenon initiates self-perpetuating renal injury [15]. Epidemiological studies of retinopathy have shown some effect of prepubertal duration of diabetes but without the long term follow-up analysis obtained here [16].

The factors that might be operative around the time of puberty are therefore of interest. The growth hormone/IGF-1 axis has been implicated, all components of which are expressed in kidney. IGF-1 increases GFR in non-diabetic humans and probably contributes to renal hypertrophy [17]. However, measurements have been of serum and urine concentrations, not tissue activity. The system has effects on vascular function and is known to be related to the development of retinopathy. Activity peaks at puberty then declines in adults, so it could contribute to renal and retinal injury at puberty.

Studies in experimental animals have investigated the renal effects of androgens and oestrogens. Manipulation of the hormonal milieu indicates that it is sex steroids per se, rather than any other effects of sex, that determine the greater susceptibility of the male kidney to progressive renal disease [18]. Testosterone activates the renin-angiotensin system [19]. In humans, men appear to respond differently to infused angiotensin II compared with women. They maintain GFR at the expense of an increased filtration fraction, implying an increase in glomerular capillary pressure. Women showed a decrease in GFR, suggesting no increase in glomerular capillary pressure [20]. In type 1 diabetes, the sexes show differing responses to acute hyperglycaemia and ACE inhibition, again suggesting that women have a lower intraglomerular pressure [21].

The generation and activation of TGF- $\beta$ is widely thought to mediate the adverse effects on the kidney of several metabolic pathways. It promotes the production and reduces the breakdown of extracellular matrix in mesangium and tubule and mediates renal hypertrophy. Unlike mature animals, diabetes did not increase TGF- $\beta$ gene expression in prepubertal animals [22]. Oestrogens inhibit TGF- $\beta$ production and its effects at the transcriptional level whereas androgens promote and accelerate TGF- $\beta$ transcriptional activity [reviewed in 19]. TGF- $\beta$ stimulates synthesis of collagen in the glomerular mesangium. Oestradiol reverses TGF- $\beta$ stimulated type I and type IV collagen gene transcription and protein synthesis and stimulates mesangial metalloproteinase (MMP)-2 and MMP-9 activity. These effects result in reduced matrix accumulation [23].

Protein kinase $\mathrm{C}$ (PKC) increases TGF- $\beta$ activity. Hyperglycaemia increases synthesis of diacylglycerol, which stimulates PKC, which in turn increases MAP kinase activity promoting TGF- $\beta$ transcription. Androgens and oestrogens stimulate PKC differentially in various tissues. Overexpression of PKC- $\beta 2$ increases renal weight in male compared with female mice. There is also some evidence relating activity of the polyol pathway and oxidative stress to the effect of sex steroids but few direct investigations have been carried out [19].

Thus there is evidence from basic research that sex steroids influence mechanisms thought to be important in the generation of diabetic microvascular disease. Animal models have not been, and may not be, able to show the importance of the pubertal injury shown in the human epidemiology. The Finnish Diabetic Nephropathy (FinnDiane) Study in this issue quantifies the effect of sex and shows that the influence of sex steroids on these mechanisms is likely to be of importance in human disease. A better understanding may lead to therapies. 
Non-oestrogenic oestradiol metabolites have been shown to inhibit mesangial cell proliferation and collagen synthesis in vitro and preserve renal function in animal models of diabetes [24]. The selective oestrogen receptor modulators (SERMs) can mimic the beneficial effects of oestradiol on mesangial cells [25] without the effects of oestrogen on the reproductive system. In human type 2 diabetes raloxifene appeared to limit the progression of albuminuria [26].

The microangiopathy of diabetic nephropathy and retinopathy occurs only in diabetes and is related to hyperglycaemia. This does not explain the sex differences seen in these epidemiological studies since glycaemic control is no worse in teenage boys than girls. But studies continue to show greater hyperglycaemia in adolescence than at other ages [27]. Intensive management of this and other well recognised modifiable risk factors is required at puberty.

Duality of interest The author declares that there is no duality of interest associated with this manuscript.

\section{References}

1. Harjutsalo V, Maric C, Forsblom C, Thorn L, Waden J, Groop PH; on behalf of the FinnDiane Study Group (2011) Sex-related differences in the long-term risk of microvascular complications by age at onset of type 1 diabetes. Diabetologia. doi:10.1007/ s00125-011-2144-2

2. Mollsten A, Svensson M, Waernbaum I et al (2010) Cumulative risk, age at onset, and sex-specific differences for developing endstage renal disease in young patients with type 1 diabetes. Diabetes 59:1803-1808

3. Harvey JN, Allagoa B (2004) The long-term renal and retinal outcome of childhood-onset type 1 diabetes. Diabet Med 21:26-31

4. Amin R, Schultz C, Ong K et al (2003) Low IGF-1 and elevated testosterone during puberty in subjects with type 1 diabetes developing microalbuminuria in comparison to normoalbuminuric control subjects. Diabetes Care 26:1456-1461

5. Maric C, Forsblom C, Thorn L, Waden J, Groop PH (2010) Association between testosterone, estradiol and sex hormone binding globulin levels in men with type 1 diabetes with nephropathy. Steroids 75:772-778

6. Haffner SM, Klein R, Dunn JF, Moss SE, Klein BEK (1990) Increased testosterone in type 1 diabetic subjects with severe retinopathy. Ophthalmology 97:1270-1274

7. Haffner SM, Klein R, Moss SE, Klein BEK (1993) Sex hormones and the incidence of severe retinopathy in male subjects with type 1 diabetes. Ophthalmology 100:1782-1786

8. Writing team for the Diabetes Control and Complications Trial/ Epidemiology of Diabetes Interventions and Complications Research Group (2003) Sustained effect of intensive treatment of type 1 diabetes mellitus on development and progression of diabetic nephropathy. The Epidemiology of Diabetes Interventions and Complications (EDIC) Study. JAMA 290:2159-2167

9. Krowleski AS, Warram JH, Christlieb AR, Busick EJ, Kahn CR (1985) The changing natural history of nephropathy in type 1 diabetes. Am J Med 78:785-794

10. Schultz CJ, Neil HAW, Dalton RN, Dunger DB (2000) Risk of nephropathy can be detected before the onset of microalbuminuria during the early years after diagnosis of type 1 diabetes. Diabetes Care 23:1811-1842

11. Barkai L, Vamosi I, Lukacs K (1998) Enhanced progression of urinary albumin excretion in IDDM during puberty. Diabetes Care 21:1019-1023

12. Janner M, Knill SE, Diem P, Zuppinger KA, Mullis PE (1994) Persistent microalbuminuria in adolescents with type 1 (insulindependent) diabetes mellitus is associated to early rather than late puberty. Eur J Pediatr 153:403-408

13. Ellis EN, Warady BA, Wood EG et al (1997) Renal structuralfunctional relationships in early diabetes mellitus. Pediatr Nephrol 11:584-591

14. Bangstad HJ, Osterby R, Rudberg S, Hartmann A, Brabrand K, Hanssen KF (2002) Kidney function and glomerulopathy over 8 years in young patients with type 1 (insulin-dependent) diabetes mellitus and microalbuminuria. Diabetologia 45:253-261

15. Hostetter TH, Rennke HG, Brenner BM (1982) The case for intrarenal hypertension in the initiation and progression of diabetic and other glomerulopathies. Am J Med 72:375-380

16. Holl RW, Lang GE, Grabert M, Heinze E, Lang GK, Debatin KM (1998) Diabetic retinopathy in pediatric patients with type 1 diabetes: effect of diabetes duration, prepubertal and pubertal onset of diabetes, and metabolic control. J Pediatr 138:790-794

17. Bacci S, de Cosmo S, Garruba M et al (2000) Role of insulin-like growth factor (IGF)-1 in the modulation of renal haemodynamics in type 1 diabetic patients. Diabetologia 43:922-926

18. Neugarten J, Kasiske B, Silbiger SR, Nyengaard JR (2002) Effects of sex on renal structure. Nephron 90:139-144

19. Lane PH (2002) Diabetic kidney disease: impact of puberty. Am J Physiol Renal Physiol 283:F589-F600

20. Miller JA, Anacta LA, Cattran DC (1999) Impact of gender on the renal response to angiotensin II. Kidney Int 55:278-285

21. Cherney DZ, Sochett EB, Miller JA (2005) Gender differences in renal responses to hyperglycaemia and angiotensin converting enzyme inhibition in diabetes. Kidney Int 68:1722-1728

22. Lane P, Snelling D, Hollman A, Langer W (2001) Puberty permits increased expression of renal transforming growth factor- $\beta 1$ in experimental diabetes. Pediatr Nephrol 16:1033-1039

23. Neugarten J (2002) Gender and the progression of renal disease. J Am Soc Nephrol 13:2807-2809

24. Zhang X, Youhong J, Jackson EK, Tofovic SP (2007) 2Methoxyestradiol and 2-ethoxyestradiol retard the progression of renal disease in aged, obese, diabetic ZSF rats. J Cardiovasc Pharmacol 49:56-63

25. Guccione M, Silbiger S, Lei J, Silbiger SR (2001) Estradiol up regulates mesangial cell MMP-2 activity via transcription factor AP-2. Am J Physiol 282:F1-F6

26. Hadjadj S, Gourdy P, Zaoui P et al (2007) Effect of raloxifene-a selective oestrogen receptor modulator - on kidney function in post-menopausal women with type 2 diabetes: results from a randomized, placebo-controlled pilot trial. Diabet Med 24:906910

27. O'Hagan M, Harvey JN (2010) Glycaemic control in children with type 1 diabetes in Wales. Diabetes Care 33:1724-1726 